\title{
Does More Information Lead to Better Informing?
}

\author{
Meliha Handzic \\ The University of New South Wales, Australia
}

m.handzic@unsw.edu.au

\begin{abstract}
This study investigated the impact of increased information availability on people's ability to process and use information in a judgemental decision making task context. The main findings indicate that increased availability had a detrimental effect on people's information processing efficiency. This, in turn, led to reduced decision accuracy. These findings have important practical implications, as they emphasise the danger of ever increasing information supply enabled by new technology. The findings also suggest a need for future research aimed at improving people's ability to make sense of the available information.
\end{abstract}

Keywords: information availability, information utilisation, decision making

\section{Introduction}

Managerial decision making is regarded as an information intensive activity. Decision makers' are often informed about their task relevant factors by the repositories of business intelligence available in their organisations, and acquire know-how in response to the demands of their work.

It is argued that the availability of environment and organisation specific information as well as a variety of causeeffect relationships can play an important role in improving decision quality. The value of such information may be seen primarily in its ability to explain past and anticipate future changes in the behaviour of the variable of interest, thus enabling the decision maker to deal more competently with his or her decision task. This is a convincing argument for suggesting that the availability of increased amounts of valid information in codified organisational databases should increase the decision maker's knowledge base and consequently improve individual decision performance.

However, processing of increased amounts of task information is a cognitive task that induces higher demands on

Material published as part of this proceedings, either on-line or in print, is copyrighted by the author with permission granted to the publisher of Informing Science for this printing. Permission to make digital or paper copy of part or all of these works for personal or classroom use is granted without fee provided that the copies are not made or distributed for profit or commercial advantage AND that copies 1) bear this notice in full and 2) give the full citation on the first page. It is permissible to abstract these works so long as credit is given. To copy in all other cases or to republish or to post on a server or to redistribute to lists requires specific permission from the author. the mental resources of the decision maker and increases the complexity of the decision problem. This in turn may affect the nature of information utilisation and performance.

With modern technology generating a growing abundance of information, it is of particular interest to this study to examine whether and how increased information availability in computerised information stores may affect individual decision makers' working knowledge, and what impact this may have on the quality of their subsequent decisions.

\section{Past Empirical Research}

Past empirical studies indicate inconclusive findings. Some studies have reported greater accuracy as a result of increased information availability. One such study (Peterson and Pitz, 1988) examined the impact of the amount of information on the ability of undergraduate students to predict the results of baseball teams. It found that an increased information base led to greater confidence and greater accuracy. Furthermore, another study (Casey, 1980) found that loan officers provided with a moderate amount of information made significantly more accurate predictions of bankruptcy than those with less information, even though these accuracy gains did not occur in the information rich group.

In contrast, a number of studies reported that increasing information brought about a significant increase in confidence without an increase in the accuracy. This was true for clinical judgements (Oskamp, 1965) and sport results predictions (Paese and Sniezek, 1991). Negligible effects of the amount of information on decision accuracy were also reported in a sampling task (Levine et al., 1975) and 


\section{More Information}

predictions from accounting reports (Snowball, 1980). Similarly, some more recent studies found no significant change in decision quality at different information levels (Simnett, 1996), and reported a lack of improvement in production decisions despite a broader information base (Handzic, 1997).

Other studies reported an actual decrease in performance with increased amounts of information. One such study (Davis et al., 1994) found that redundant information made subjects substantially more confident in their forecasts of stock earnings and that nonredundant information made them even more confident. Forecast accuracy, however, was substantially diminished with both redundant and nonredundant information. Thus, additional information had the effect of degrading performance while increasing confidence. The dysfunctional role of increased information also was seen in a study of decision makers' production cost (Chervany and Dickson, 1974). Those with a larger amount of raw data made poorer quality decisions which resulted in greater production costs, but had more confidence in the quality of their decisions. In similar production decision tasks, two more studies (Connolly and Thorn, 1987) both reported gradually decreasing efficiency of information use with greater information availability.

The review of past empirical research shows that performance sometimes followed an inverted $U$ relationship with information amount as proposed by some theorists (Schroder et al., 1967; Wood, 1986). Sometimes, it declined monotonically, consistent with the strategy selection model suggested by the decision-making literature (Beach and Mitchell, 1978; Christensen-Szalanski, 1978; Payne, 1982), and sometimes showed no change at all. It was suggested (Hwang and Lin, 1999) that mixed results might be due to the fact that information load was a function of other information dimensions such as diversity and repetitiveness. The inconsistent findings may also be attributed to different measures of performance such as absolute or relative, as well as different task environments. A series of simulation studies (Payne et al., 1988; Payne et al., 1990) tested the performance of a number of heuristics in a choice task. The results indicated that the level of performance of various heuristics was highly contingent upon the task environment characteristics.

In view of the inconsistent prior findings and concerns expressed, the main objective of the current study is to examine the impact of increased amounts of valid computerised information of similar importance on individual decision performance in a controlled task environment. In particu- lar, the study will examine (i) whether and how increased information availability in the computerised information stores will affect the decision makers' information processing efficiency, and (ii) whether and how it may impact the quality of their subsequent decisions.

\section{Research Methodology}

\section{Experimental task}

The experimental task in the current study was a simple production planning activity in which subjects made decisions regarding daily production of fresh ice cream. The participants assumed the role of Production Manager for a fictitious dairy firm that sold ice cream from its outlet at Bondi Beach in Sydney, Australia. The fictitious company incurred equally costly losses if production was set too low (due to loss of market to the competition) or too high (by spoilage of unsold product). The participants' goal was to minimise the costs incurred by incorrect production decisions. During the experiment, participants were asked at the end of each day to set production quotas for ice cream to be sold the following day. Subjects were required to make thirty production decisions over a period of thirty consecutive days. Before commencing the task, participants had an opportunity to make five trial decisions (for practice purposes only).

From pre-experiment discussions with actual store owners at Bondi Beach, three factors emerged as important in determining local demand for product: the ambient air temperature, the amount of sunshine and the number of visitors/tourists at the beach. Varying amounts of contextual cues were provided to subjects. One half of the participants received only one contextual information cue, and another half received all three cues. All cues were deemed equally reliable in predicting daily product demand.

The task provided a challenge because it did not stipulate exactly how information should be translated into specific judgement. The participants were provided with a meaningful task context, sequential historic information of task relevant variables to provide some clues to causal relationship, and forecast values of contextual variables to suggest future behaviour. However, they were not given any explicit analysis of the quality of their information, or rules they could apply to integrate the available factual information.

At the beginning of the experiment, task descriptions were provided to inform subjects about the task scenario and requirements. The given text differed with respect to the 
quantity of contextual information provided. In addition, throughout the experiment instructions and feedback were provided to each participant to analyse earlier performance and to adjust future strategies.

\section{Experimental design and variables}

A laboratory experiment with random assignment to treatment groups was used, since it allowed greater experimental control. This made it possible to draw stronger inferences about causal relationships between variables due to high controllability. The only independent variable was information availability (small amount versus large amount).

Information availability was manipulated by changing the amount of contextual information (one cue versus three cues) provided to participants in a computerised database.

All information cues were decision-relevant. The results of stepwise regressions showed R-square values of 0.66 $(\mathrm{F}(1,28)=55.62, \mathrm{p}=.000)$ with only one of the cues, and $0.87(\mathrm{~F}(3,26)=56.82, \mathrm{p}=.000)$ with all three cues in the equation.

Individual performance was evaluated in terms of processing efficiency of the available information and decision accuracy achieved as a result. Processing efficiency was operationalised by a relative to optimal error (ROE) and was calculated as a ratio of an absolute error of a person's decision to the corresponding error of the "optimal strategy". The optimal strategy was modelled using stepwise regressions with one (or three) contextual variables as independent variables and sales data as the dependent variable. The optimal response integrates individual variables into a single response using regression weights and produces the best possible performance given the available information. ROE were calculated to assess how much of the maximum information potential was extracted and used by the subjects. Scores equal to 1 indicate maximal, while scores greater than 1 indicate suboptimal processing efficiency.

Decision accuracy was operationalised by a relative to naive error (RNE) and was calculated as a ratio of an absolute error of a person's decision to the corresponding error of the "random walk" (naive) strategy (for details see Amstrong and Collopy, 1992). A naive strategy is one that simply determines the next day sales as equal to the current day's sales. Such strategy makes no use of any contextual information and typically produces poor performance. RNE was used to assess improvement in the quality of de- cisions due to information use. Scores equal to 1 indicated no improvement, while scores smaller than one indicated improved accuracy.

\section{Subjects and procedure}

The subjects were 28 graduate students enrolled in the Master of Commerce course at the University of New South Wales, Sydney. Subjects participated in the experiment on a voluntary basis and received no monetary incentives for their performance. Generally, graduate students are considered to be appropriate subjects for this type of research (Ashton and Kramer, 1980; Remus, 1996; Whitecotton, 1996). The experiment was conducted in a microcomputer laboratory. On arrival, subjects were assigned randomly to one of the treatment groups by picking up a diskette with an appropriate version of the research instrument to be used. The instrument was specifically developed by the author in Visual Basic. Subjects were briefed about the purpose of the study, read the case descriptions and performed the task. The session lasted about one hour.

\section{Results}

The analysis of collected data was performed using a series of T-tests to examine the effects of information availability on two dependent variables of interest (processing efficiency and decision quality). The results are presented in Table 1.

The results of the analysis shown in Table 1 indicate a significant detrimental effect of increased information avail-

\begin{tabular}{|lccccc|}
\hline $\begin{array}{l}\text { Information } \\
\text { Availability }\end{array}$ & $\begin{array}{c}\text { Small } \\
(\mathrm{N}=420)\end{array}$ & $\begin{array}{c}\text { Large } \\
(\mathrm{N}=420)\end{array}$ & & \\
\hline $\begin{array}{l}\text { Dependent } \\
\text { Variable }\end{array}$ & $\begin{array}{c}\text { Mean } \\
(\mathrm{Std})\end{array}$ & $\begin{array}{c}\text { Mean } \\
(\mathrm{Std})\end{array}$ & $\mathrm{t}$ & $\mathrm{p}$ \\
\hline $\begin{array}{l}\text { Processing } \\
\text { Efficiency } \\
\text { (ROE) }\end{array}$ & 2.70 & 4.00 & -5.89 & $.000^{*}$ \\
$\begin{array}{l}\text { Decision Ac- } \\
\text { curacy (RNE) }\end{array}$ & $\begin{array}{c}.94 \\
(1.15)\end{array}$ & $\begin{array}{c}(3.53) \\
(1.65)\end{array}$ & & & \\
\hline *p <.05 & & & & \\
$\begin{array}{l}\text { Table 1: Information availability effects on process- } \\
\text { ing efficiency and decision accuracy }\end{array}$ \\
\hline
\end{tabular}




\section{More Information}

ability on processing efficiency. The mean ROE of the subjects with the larger information amounts was significantly higher than that of the subjects with the smaller information amounts (4.00 versus 2.70, $\mathrm{t}=-5.89, \mathrm{p}<.05$ ). Mean values greater than 1 indicated that subjects processed information less efficiently than they could have irrespective of variations in information availability.

Table 1 also shows a significant negative effect of increased information availability on decision accuracy. The subjects with the larger information amounts had a significantly higher mean RNE than their counterparts with the smaller information amounts (1.15 versus .94, $\mathrm{t}=-2,13$, $\mathrm{p}<.05)$. Mean values less than 1 indicate marginal improvement in decision accuracy compared to naive strategy due to information utilisation.

\section{Discussion}

The findings of this study provide no support for the proposition that a broader supply of factual information will enhance individual working knowledge and improve performance in a decision-making task context. The study has demonstrated that an increased availability of factual information had a detrimental effect on processing efficiency. Subjects provided with larger amounts of factual information tended to utilise their available information relatively less efficiently compared to those with smaller amounts. This was demonstrated by significantly greater processing errors found among the subjects from the larger than from smaller information availability groups.

Consistent with a severely reduced processing efficiency, the study revealed that increased information availability resulted in deteriorated decision accuracy. This was evidenced by significantly higher decision errors found among the subjects with larger than smaller information amounts. In general, these findings are consistent with the earlier theoretical work suggesting a detrimental effect of information overload (Schroder et al., 1967) and task complexity (Beach and Michell, 1978; Christensen-Szalanski, 1978; Payne, 1982; Wood, 1986) on individual performance. They are also in accord with some earlier empirical evidence of reduced efficiency (Connolly and Thorn, 1987; Handzic, 1997) and accuracy (Chervany and Dickson, 1974; Davis et al., 1994) with increased information volumes.

With respect to overall performance, the study revealed relatively inefficient use of the available information across both treatments, which consequently resulted in little or no real improvement in decision accuracy over naive strategy. The relatively poor overall performance could be potentially attributed to the lack of monetary incentives. Other studies (Handzic, 1997) provided their students with substantial monetary rewards for their performance. It is possible that without monetary incentives, the subjects did not try as hard as possible to use the full potential of their information to improve decisions. This is offset by the assumption that graduates chosen from the pool of students attending an advanced Master's level course should be motivated to do their best on the task by their intrinsic interest in the subject matter.

Alternatively, poor overall performance could be attributed to the characteristics of the task information and the task performers. Computerised information repositories available to participants in the current study contained only factual information with little analysis, and had no procedural information. Internalising factual information into "explicit" knowledge was insufficiently achieved to perform well on the task. The participants also needed analytical information such as an evaluation of the predictive validity of each contextual factor, as well as the relevant know-how to integrate factual information into a decision response. This crucial information was assumed to be a part of an individual's "tacit" knowledge. However, non-expert participants appear not to have had high levels of the required "tacit" knowledge to perform well on the task without prior training or experience.

While the current study provides a number of interesting findings, some caution is necessary regarding their generalisability due to a number of limiting factors. One of the limitations refers to the use of a laboratory experiment that may compromise external validity of research. Another limitation relates to artificial generation of information that may not reflect the true nature of real business. The subjects chosen for the study were students and not real life decision makers. Although the fact that they were mature graduates may mitigate the potential differences. Also, no incentives were offered to the subjects for their effort in the study. Consequently, subjects could have found the study tiring and unimportant and may not have tried as hard as possible. Most decisions in real business settings have significant consequences which contributes to motivate the decision makers.

Although limited, the findings of the current study may have some important implications for organisational information management strategies. They indicate that the decision makers overwhelmed by the abundance of computerised information provided to them may resolve to ap- 


\section{Meliha Handzic}

ply extremely simple intuitive decision strategies, completely avoiding the use of much of their information. The findings also suggest a need for measures aimed at improving information consumption.

\section{Conclusions}

The main objective of this study was to investigate the effect of information availability on people's ability to process and use relevant factual information to improve performance in a specific decision making context. In summary, the findings of the study indicate that increased availability of information had a detrimental effect on both processing efficiency and decision accuracy of individual decision makers. These findings have important implications for practitioners, as they emphasise the danger of dramatic increases in information supply enabled by new technology. Further research is required that would look at ways to improve people's ability to make sense of the available information and turn it into useful knowledge.

\section{References}

Amstrong, J.S., \& Collopy, F. (1992). Error Measures for Generalising about Forecasting Methods: Empirical Comparisons. International Journal of Forecasting, 8, 69-80.

Ashton, R.H., \& Kramer, S.S. (1980). Students as Surrogates in Behavioural Accounting Research: Some Evidence. Journal of Accounting Research, 18(1), 1-15.

Beach, L.R., \& Mitchell, T.R. (1978). A Contingency Model for the Selection of Decision Strategies. Academy of Management Review, July, 439-449.

Casey, C.J.Jr. (1980). Variation in Accounting Information Load: The Effect on Loan Officers' Predictions of Bankruptcy. The Accounting Review, 52(1), 36-49.

Chervany, N.L. , \& Dickson, G.W. (1974). An Experimental Evaluation of Information Overload in a Production Environment. Management Science, 20(10), 62-71.

Christensen-Szalanski, J.J.J. (1978). Problem Solving Strategies: A Selection Mechanism, Some Implications, and Some Data. Organisational Behaviour and Human Performance, 22, 307-323.

Connolly, T., \& Thorn, B.K. (1987). Predecisional Information Acquisition: Effects of Task Variables on Suboptimal Search Strategies. Organisational Behaviour and Human Decision Processes, 39, 397-416.

Davis, F.D., Lohse, G.L., \& Kottemann, J.E. (1994). Harmful Effects of Seemingly Helpful Information on Forecasts of Stock Earnings. Journal of Economic Psychology, 15, 253-267.
Handzic, M. (1997). Decision Performance as a Function of Information Availability: An Examination of Executive Information Systems. Proceedings of the 2nd New South Wales Symposium on Information Technology and Information Systems, Sydney: UNSW.

Hwang, M.I., \& Lin, J.W. (1999). Information Dimension, Information Overload and Decision Quality. Journal of Information Science, 25(3), 213-218.

Levine, J.M., Samet, M.G., \& Brahlek, R.E. (1975). Information Seeking with Limitations on Available Information and Resources. $\mathrm{Hu}$ man Factors, 17(5), 502-513.

Oskamp, S. (1965). Overconfidence in case-study judgements. Journal of Consulting Psychology, 29, 261-265.

Paese, P.W., \& Sniezek, J.A. (1991). Influences on the Appropriateness of Confidence in Judgement: Practice, Effort Information and Decision Making. Organisational Behaviour and Human Decision Processes, 48, 100-130.

Payne, J.W. (1982). Contingent Decision Behaviour. Psychological Bulletin, 92(2), 382-402.

Payne, J.W., Bettman, J.R., \& Johnson, E.J. (1988). Adaptive Strategy Selection in Decision Making. Journal of Experimental Psychology, 14(3), 534-552.

Payne, J.W., Johnson, E.J., Bettman, J.R., \& Coupey E. (1990). Understanding Contingent Choice: A Computer Simulation Approach. IEEE Transactions on Systems, Man and Cybernetics, 20(2), March/April, 296-309.

Peterson, D.K., \& Pitz, G.F. (1988). Confidence, Uncertainty and the Use of Information. Journal of Experimental Psychology: Learning, Memory and Cognition, 14, 85-92.

Remus, W. (1996). Will Behavioural Research on Managerial Decision Making Generalise to Managers? Managerial and Decision Economics, 17, 93-101.

Schroder, H.M., Driver, M.J. , \& Streufert, S. (1967). Human Information Processing. Holt, Rinehart and Winston Inc.

Simnett, R. (1996). The Effect of Information Selection, Information Processing and Task Complexity on Predictive Accuracy of Auditors. Accounting, Organisation and Society, 21, 699-719.

Snowball, D. (1980). Some Effects of Accounting Expertise and Information Load: An Empirical Study. Accounting, Organisation and Society, 5, 323-338.

Whitecotton, S.M. (1996). The Effects of Experience and a Decision Aid on the Slope, Scatter, and Bias of Earnings Forecasts. Organisational Behaviour and Human Decision Processes, 66(1), 111121.

Wood, R.E. (1986). Task Complexity: Definition of the Construct. Organisational Behaviour and Human Decision Processes, 37(1), 6082. 


\section{More Information}

\section{Biography}

Meliha Handzic is a faculty member of The University of New South Wales, where she teaches a number of graduate courses in information systems, technology and management. Her main research interests include knowledge management and decision making. 